\title{
Composition of Lipophylic Extracts from Two Tunicates, Styela sp. and Phallusia sp. from the Eastern Mediterranean
}

\author{
Krasimir Slantcheva ${ }^{\mathrm{a}}$, Funda Yalçın ${ }^{\mathrm{b}}$, Tayfun Ersöz ${ }^{\mathrm{b}}$, Jordan Nechev ${ }^{\mathrm{a}}$, \\ İhsan Çalış ${ }^{\mathrm{b}}$, Kamen Stefanov ${ }^{\mathrm{a}}$ and Simeon Popov ${ }^{\mathrm{a}, *}$ \\ a Institute of Organic Chemistry with Centre of Phytochemistry, \\ Bulgarian Academy of Sciences, 1113 Sofia, Bulgaria \\ b Hacettepe University, Faculty of Pharmacy, Department of Pharmacognosy, \\ 06100 Ankara, Turkey \\ * Author for correspondence and reprint requests \\ Z. Naturforsch. 57 c, 534-540 (2002); received January 18/February 27, 2002 \\ Sterols, Tunicates, Volatiles
}

Sterols, volatiles and lipids were isolated and identified from lipophylic extracts from two tunicates, Styela sp. and Phallusia sp., occurring in the Eastern Mediterranean. Seventeen sterols were identified. The sterol composition of the two organisms appeared to be similar except for the concentrations of $5 \alpha$-stanols. Both tunicates were characterized by the presence of sterols with a (22Z)-double bond. In the volatiles significant amounts of chlorinated compounds were found (phenols in Styela sp. and hydrocarbons in Phallusia sp.). The fatty acid composition of triacylglycerols and phospholipids of the two tunicates showed significant differences.

\section{Introduction}

The subphylum Urochordata, in which tunicates are included, contains about 2500 species, divided into three classes, Thaliacea, Larvacea and Ascidiacea. Until now investigations on the chemical composition of tunicates are almost exclusively concentrated on Ascidiacea, commonly called "sea squirts". They are sessile inhabitants of the sea bottom from the intertidal zone to a depth of $6000 \mathrm{~m}$. Depending on the species they may be either solitary or colonial and most of them are monoecious. All of them are filter feeders. The investigations on their chemical composition were concentrated mainly on secondary metabolites, because they have proved themselves as a rich source of biologically active compounds (Faulkner, 1995). However, no sufficient information on their lipid and sterol composition is available. These compounds are of interest as constituents of cell membranes, and the membrane functions depend on the lipid and sterol composition. The sterol mixtures isolated from tunicates, analogously to other marine invertebrates, are very complex, contrary to those in vertebrates and to most of the evolutionary higher invertebrates (insecta, crustacea, cephalopoda, etc.)
Only sterols from the class of Ascidiacea, suborder Stolidobronchiata, have been investigated so far. Recently the sterol composition of tunicates has been compared and a chemotaxonomic scheme of tunicates has been proposed (Slantchev et al., 2000). It appeared that sterol composition of tunicates have some common characteristics presence of significant amounts of stanols, including in some cases coprostanol type stanols. Cholesterol and cholestanol were assumed to be the main sterols, followed by brassicasterol (Slantchev et al., 2000; Ballantine et al., 1977). Ergosterol-type sterols and 4-methyl sterols were also found (Zollo et al., 1986). According to their sterol composition, tunicates were proposed to divide into three groups. The first one included tunicates from families Tethyidae and Pyuridae, the second group included families Ascidiidae, Botryllidae, Cionidae and Molgulidae, and the third group included family Styelidae. These conclusions were based on a limited number of investigated species and future investigations are necessary to confirm or reject the proposed classification.

There are limited data on the lipid composition of tunicates. It appears that they have a normal fatty acid composition, characteristic for higher plants and invertebrates (Kostetsky and Naumenko, 1984). Phospholipids in Styela clava con- 
tain mainly phosphatidylcholine (PC) $(54.5 \%)$ and phosphatidylethanolamine (PE) $(24.0 \%)$, as well as significant concentrations of phosphatidylethanolamine plasmalogens (Kostetsky and Naumenko, 1984; Dembitsky, 1979). The representatives of family Ascidiidae contain more PE than the tunicates from other families (Kostetsky et al., 1983).

The volatile constituents of marine invertebrates are of interest, because such compounds often possess a valuable biological activity. Preliminary research on some Black Sea invertebrates and algae, showed that they contain very complex mixtures of volatile compounds (Popov et al., unpubl. results). Most of them were new for the investigated species and some of them were known to possess biological activity, mainly antibacterial and antifungal. This was an indication that they could have defensive functions. The volatiles are produced mainly from algae, especially cyanobacteria and microalgae (Dembitsky et al., 1999) and their analysis in invertebrates could give some information about the food chains in the sea. Very little is known about the volatile constituents of tunicates. Recently it was found that the Black Sea tunicate, Botryllus schlosseri, contrary to other invertebrates and algae, possesses a very simple composition of volatiles - only six compounds were identified and except 2,3-butanediol all others were hydrocarbons and fatty acid methyl esters (Slantchev et al., 2000a).

\section{Materials and Methods}

\section{General experimental procedures}

GC (for sterols): Pye Unicam 304, equipped with a FID and a capillary column SPB-1 (30 $\mathrm{m} \times$ $0.32 \mathrm{~mm}, 0.25 \mu \mathrm{m}$ film). Temperature program: $230{ }^{\circ} \mathrm{C}-300{ }^{\circ} \mathrm{C}$ at $4{ }^{\circ} \mathrm{C} \min ^{-1}$ and a $10 \mathrm{~min}$ hold. Injector temperature: $300^{\circ} \mathrm{C}$. Detector temperature: $320^{\circ} \mathrm{C}$. Carrier gas: $\mathrm{N}_{2}$, linear velocity: $35 \mathrm{~cm} \cdot \mathrm{sec}^{-1}$. For fatty acid methyl esters: SILAR $10 \mathrm{C}$ capillary column, $30 \mathrm{~m}, 0.2 \mathrm{~mm}$ i.d.

GC/MS (for sterols): Hewlett Packard $6890+$ MS5973 at 70 ev with a capillary column SPB-50 (30 $\mathrm{m} \times 0.32 \mathrm{~mm}, 0.25 \mu \mathrm{m}$ film). Carrier gas: He, temperature program: $270^{\circ} \mathrm{C}-290{ }^{\circ} \mathrm{C}$ at $4{ }^{\circ} \mathrm{C}$ $\min ^{-1}$ and a 20 min hold.

GC/MS (for volatiles): Hewlett Packard $6890+$ MS5973 with a capillary column HP-5MS (30 m $\times$
$0.32 \mathrm{~mm}, 0.25 \mu \mathrm{m}$ film). Carrier gas: He, temperature program: $40{ }^{\circ} \mathrm{C}-280{ }^{\circ} \mathrm{C}$ at $6^{\circ} \mathrm{C} \mathrm{min}$ min $^{-1}$ and $10 \mathrm{~min}$ hold.

${ }^{1} \mathrm{H}$ NMR measurements in $\mathrm{CDCl}_{3}$ were performed on a Bruker instrument, operating at 250 $\mathrm{MHz}$

\section{Samples.}

Styela sp. were collected by hand using scuba diving from Kaş (Turkey) in May 1999 at a depth of 2-8 m. Phallusia sp. were collected by hand using scuba diving from Antalya (Turkey) in May 1999 at a depth of 5-20 m.

\section{Isolation and analysis of sterols}

A sample (300 g) from Styela sp. was homogenized in EtOH (31), and after the addition of $\mathrm{CH}_{2} \mathrm{Cl}_{2}$ (3 1) the mixture was filtered and some water was added. The residue was then washed with $\mathrm{CH}_{2} \mathrm{Cl}_{2}(3 \times 1000 \mathrm{ml})$. All $\mathrm{CH}_{2} \mathrm{Cl}_{2}$ layers were combined and evaporated at $40{ }^{\circ} \mathrm{C}$ under reduced pressure yielding $3 \mathrm{~g}$ dry extract. Part of the dry extract $(1 \mathrm{~g})$ was subjected to $\mathrm{CC}$ on silica gel $(40 \mathrm{~g})$ and fractionated with $\mathrm{CHCl}_{3}-\mathrm{MeOH}$ mixtures in ascending polarity $\left(\mathrm{CHCl}_{3}-\mathrm{MeOH}\right.$ 95:5 $\rightarrow \mathrm{MeOH} 100 \%, 20 \mathrm{ml}$ each). The fraction eluted with $\mathrm{CHCl}_{3}-\mathrm{MeOH}$ 95:5 was rechromatographed over silica gel using $\mathrm{CHCl}_{3}$ as eluent. Fractions containing sterols were identified by TLC and combined. Preparative TLC on silica gel with diethyl ether:hexane $(1: 1 \mathrm{v} / \mathrm{v})$ achieved final purification of the total sterol fractions. The total sterol mixtures were investigated by $\mathrm{GC}, \mathrm{GC} / \mathrm{MS}$ and ${ }^{1} \mathrm{H}-\mathrm{NMR}$.

A sample from Phallusia sp. (500 g) was homogenized in EtOH (31), and prepared as described for Styela sp. above.

\section{Isolation and analysis of volatiles}

Part of the dry $\mathrm{CH}_{2} \mathrm{Cl}_{2}$ extract $(1 \mathrm{~g})$ from Styela sp. was subjected to distillation - extraction for four hours using a Liken-Nickerson apparatus (Hendriks et al., 1981). The collected distillates were extracted with diethyl ether and the extracts dried over $\mathrm{Na}_{2} \mathrm{SO}_{4}$ and evaporated. The procedure described for Styela sp. was repeated with $1 \mathrm{~g}$ of the dry $\mathrm{CH}_{2} \mathrm{Cl}_{2}$ extract from Phallusia. The obtained volatiles $(0.010 \mathrm{~g} ; 1 \%$ of the lipophylic ex- 
tract of Phallusia sp. and $0.012 \mathrm{~g} 1.2 \%$ of Styela sp.) were investigated by GC/MS.

Isolation and analysis of the main lipid classes and their fatty acids

Parts of the methylene chloride extracts from both tunicates (each $0.1 \mathrm{~g}$ dry weight), were separated by preparative TLC on Si gel G plates with chloroform-methanol-acetone-acetic acid (35:7: 12:0.2 v/v/v ) as mobile phase. The spots of the main lipid classes were identified by their chromatographic behavior, compared to authentic samples, and by specific spray reagents. The zones of the main lipid classes were scraped off into small glass containers with teflon screw caps. After addition of an internal standard (heptadecanoic acid) all lipid classes were preesterified with $15 \%$ acetylchloride in methanol according to Christie (1973). To determine the amount of each lipid class the weights of FAME were multiplied by a K-factor (Elenkov et al. 1993)

\section{Results and Discussion}

Sterols

The free sterol fractions were isolated by column chromatography of the total lipophylic extracts and purified by preparative TLC. Quantitative analysis were performed by GC, while the individual sterols were identified by GC/MS and GC relative retention times (RRT) (Table I). The methods used are applied in almost all investigations on sterol mixtures. There were several problems, which arose when complex sterol mixtures were investigated. The first one was the identification of the stanols, present in the mixture. While $5 \beta$-stanols have different RT values on the GC column, the most common, $5 \alpha$-stanols, have a practically identical RRT with the corresponding $\Delta^{5}$-sterols (1.01 for $5 \alpha$-cholestanol and 1.0 for cholesterol) and could not be separated well even on a capillary column. The mass spectra of the investigated sterols showed a presence of stanols, mixed with the corresponding $\Delta^{5}$-sterols, but all attempts we made to use the ratio of the peaks, characteristic for both groups of compounds, for quantitative analysis were unsuccessful. For this reason we have investigated the total sterol mixtures by ${ }^{1} \mathrm{H}$ NMR and the ratio of the peak areas for $\mathrm{H}-3$ and H-6 gave the concentration of the $5 \alpha$-stanols in the sterol mixture. The second problem was the determination of the stereochemistry of the C-22 double bond. More than twenty years ago some investigators reported the presence of sterols with 22Z-double bonds (Goad, 1978), but later some authors pointed out that previous reports on $22 Z$ double bond were questionable and in some cases other sterol isomers were present (Schmitz, 1977).

Table I. Sterol composition of Styela sp. and Phallusia sp. (\% of total sterol mixture).

\begin{tabular}{|c|c|c|}
\hline Sterol & Styela & Phallusia \\
\hline 27 Nor-24-methyl-cholesta-5,22-dien-3 $\beta$-ol & 2.3 & 0.3 \\
\hline 27 Nor-24-methyl-cholest-22-en-3 $\beta$-ol & traces & - \\
\hline (22E-cholesta-5,22-dien-3 $\beta$-ol & 3.1 & 3.4 \\
\hline Cholesterol & 42.3 & 32.0 \\
\hline $5 \alpha$ Cholestan 3 $\beta$-ol & 4.0 & 16.0 \\
\hline (22Z)-24-methyl-cholesta-5,22-dien-3ß-ol & 9.0 & 10.0 \\
\hline Cholestan-3-one & traces & - \\
\hline 24-Methyl-cholest-22-en-3 $\beta$-ol & 0.8 & 5.0 \\
\hline 24-Methyl-cholest-5-en-3 $\beta$-ol & 3.7 & - \\
\hline 24-Methyl-cholest-5,24(28)-dien-3 $\beta$-ol & 5.5 & 4.2 \\
\hline 24-Ethyl-cholesta-5,22-dien-3 $\beta$-ol & 3.5 & 7.0 \\
\hline 24-Ethyl-cholest-22-en-3 $\beta$-ol & traces & 3.0 \\
\hline (22E)-24-Ethyl-cholesta-5, 24(28)-dien-3 $\beta$-ol & 5.5 & - \\
\hline 24-Ethyl-cholest-5-en-3 $\beta$-ol & 14.5 & 10.4 \\
\hline $5 \alpha-24$-Ethyl-cholestan-3 $\beta$-ol & 1.0 & 4.0 \\
\hline Gorgosterol & 1.6 & - \\
\hline
\end{tabular}

Trace: $<0.1 \%$ 
Recently sterols containing a $22 Z$ double bond were confirmed in a plant (Akihisa et al., 1990) and in a marine hydrozoan (De Rosa et al., 1999). The reason for such a confusion is that some of the $Z$ and $E$ isomers can be separated easily by GC (e.g. 22Z- and 22E-dehydrocholesterol), but the RT of the $22 Z$-isomer is identical with that of 27-nor-24-methyl-cholesta-5,22-dien-3 $\beta$-ol (ocellasterol) and both compounds have practically identical mass spectra. The $22 Z$ - and $22 E$-isomers of 24-methyl-cholesta-5,22-dien-3 $\beta$-ol have very close RT on GC and their peaks overlap. The only way to distinguish the isomers is their ${ }^{1} \mathrm{H}$ NMR spectra. The ratio of the both isomers can be measured from the areas of the signals for trans- and cis-olefinic protons ( $\mathrm{H}-22$ and $\mathrm{H}-23)$. The presence of 4-methyl sterols, coprostanol and ergosterol type compounds can also be proved by the $\mathrm{H}-3$ signals in the same spectra.

The obtained GC curves of the sterol mixtures from both tunicates were very similar - the main peak corresponded to cholesterol and its saturated analogue, followed by 24-methyl-cholesta-5,22-

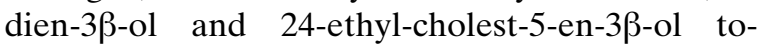
gether with their saturated analogues (see Table I). This similarity may be explained by similarity of the diet. Both tunicates were collected at May 1999, at locations situated less than $100 \mathrm{~km}$ apart, so the planctonic composition could be assumed to be identical, leading to identical diet. Significant differences were found only in the concentrations of the 5 $\alpha$-stanols. In Phallusia sp. they were about $33 \%$ of the total sterols (the remaining part of the sterols contained C-5 double bond), while in Styela there were only $8 \% 5 \alpha$-stanols. Saturated sterols are characteristic for some dinoflagellates (Volkman et al., 1999). They also could be produced by a biotransformation of the dietary $\Delta^{5}$-sterols in the tunicate organism. At least in some cases it was proved that such transformations occur. In Molgula eubrocta from the Black Sea significant concentrations of $5 \alpha$-stanols have been found, which were produced from radiolabeled cholesterol (Popov et al., 1988). Their endogenous origin was confirmed by their relatively low concentration in the digestive tract. The significant amounts of $5 \alpha$-stanols in most tunicates is an indication that they fulfill some membrane requirements and are produced by a biotransformation of the dietary $\Delta^{5}$ sterols.
Besides the concentrations of the stanols there were insignificant differences between the sterol composition of both investigated tunicates (see Table I). The concentration of 24-ethyl-cholesta5,22-dien-3 $\beta$-ol was higher in Phallusia sp. while in Styela sp. we found small amounts of cholestan-3one and gorgosterol. The presence of the first one could be due to a biotransformation leading to stanols in this organism, while the second one, found for the first time in tunicates, could be of dietary origin. No 4-methyl sterols, coprostanols and ergosterol type compounds were detected by mass spectrometry and ${ }^{1} \mathrm{H}$ NMR spectroscopy. When the sterol composition of the investigated organisms was compared with other representatives of the same genera, some significant differences have been noted. Until now there were only two reports on sterols from Phallusia mamillata. The first one describes four 9(11)-unsaturated sterol peroxides (Guyot and Durgeat, 1981). Such compounds in most cases are generated by photosensitized oxygenation of the corresponding trienes, but in this case the experiments were carried in the dark, and the isolated compounds could not be artifacts. Apparently in this investigation no attempt was made to isolate and analyze the common sterols, so no comparison could be made. The second report describes a novel 24-hydroperoxy-24-vinylcholesterol, which could result from an oxidative process (Guyot and Davoust, 1982).

The previously investigated three samples of Styela sp. from two species (Zollo et al., 1986; Goad, 1978; Elyakov and Stonik, 1988), including our samples, showed a very few differences in the sterol composition. The concentrations of the $5 \alpha-$ stanols were similar. Only in one sample coprostanol-type compounds were found. No ergosteroltype compounds have been found in representatives of the family Styelidae. The main sterol in all samples, including ours, was cholesterol.

Recently we found that in the Black Sea tunicate Botryllus schlosseri more than $90 \%$ of the sterols with a C-22 double bond were $22 Z$-isomers (Slantchev et al., 2000). Now we found that in the two tunicates, collected in the Eastern Mediterranean, the $22 Z$-isomer was about $85 \%$ of the sterols containing a C-22 double bond. Such sterols may be characteristic for tunicates, but further investigations must be performed to clarify this problem. The other sterols from the Black Sea Botryllus 
schlosseri were similar to those of Styela and Phallusia. In B. schlosseri the $5 \alpha$-stanols were the main sterols, followed by cholesterol, 24-methyl-cholesta-5,22-dien-3 $\beta$-ol and 24-methylenecholesterol (Slantchev et al., 2000). Only the last one was pres- ent in lower concentration in the investigated tunicates from the Eastern Mediterranean. Instead we found higher concentrations of sitosterol, which could be related to some differences in the diet.

Table II. Volatiles from Styela sp. and Phallusia sp. (\% of total volatiles)*.

\begin{tabular}{|c|c|c|}
\hline Compound & Styela & Phallusia \\
\hline $\begin{array}{l}\text { Alcohols } \\
\text { Ethanol-2,2'-oxybis } \\
\text { Benzyl alchohol } \\
\text { Phenol-2-methoxy }\end{array}$ & $\begin{array}{c}\mathbf{0 . 9} \\
- \\
0.2 \\
0.7\end{array}$ & $\begin{array}{l}8.8 \\
8.8 \\
-\end{array}$ \\
\hline $\begin{array}{l}\text { Chlorine-containing compounds } \\
\text { Phenol 4-chloro-3-methyl } \\
\text { Phenol-pentachloro } \\
\text { Propane,1,1,1-trichloro } \\
\text { Ethylene-tetrachloro } \\
\text { Ethane,1,1,2,2-tetrachloro } \\
\text { Ethane, pentachloro } \\
\text { Ethane, hexachloro }\end{array}$ & $\begin{array}{c}0.1 \\
3.4 \\
\text { traces } \\
4.2 \\
38.5\end{array}$ & $\begin{array}{c}\mathbf{0 . 2} \\
\text { traces } \\
0.2 \\
- \\
- \\
- \\
- \\
-\end{array}$ \\
\hline $\begin{array}{l}\text { Acids } \\
\text { Benzoic acid }\end{array}$ & $\begin{array}{l}- \\
-\end{array}$ & $\begin{array}{l}\text { traces } \\
\text { traces }\end{array}$ \\
\hline $\begin{array}{l}\text { Aldehydes } \\
\text { Decanal } \\
\text { 7-Heptadecenal }\end{array}$ & $\begin{array}{l}- \\
- \\
-\end{array}$ & $\begin{array}{r}\mathbf{1 2 . 1} \\
1.2 \\
10.9\end{array}$ \\
\hline $\begin{array}{l}\text { Ketones } \\
\text { 2,5-Cyclohexadiene-1,4-dione-2,6-bis(1,1-dimethylethyl) } \\
\text { 2-Propanone,1-(acetyloxy) }\end{array}$ & $\begin{array}{l}- \\
- \\
-\end{array}$ & $\begin{array}{c}\mathbf{6 . 8} \\
6.8 \\
\text { traces }\end{array}$ \\
\hline $\begin{array}{l}\text { Sulfur-containing compounds } \\
\text { Diethyl sulfone }\end{array}$ & $\begin{array}{l}- \\
-\end{array}$ & $\begin{array}{l}\text { traces } \\
\text { traces }\end{array}$ \\
\hline $\begin{array}{l}\text { Hydrocarbons } \\
\text { Cyclohexane-1-methyl } \\
\text { Undecane } \\
\text { Dodecane } \\
\text { Tridecane } \\
\text { Tetradecane } \\
\text { Pentadecane } \\
\text { Hexadecane } \\
\text { Cyclopentane, undecyl } \\
\text { Heptadecane } \\
\text { Pentadecane 2,6,10,14-tetramethyl } \\
\text { 1-Nonadecene } \\
\text { Octadecane } \\
\text { Nonadecane } \\
\text { Phenanthrene }\end{array}$ & $\begin{array}{c}\text { 3.0 } \\
- \\
\text { traces } \\
0.9 \\
0.1 \\
0.5 \\
0.2 \\
- \\
- \\
0.4 \\
- \\
- \\
- \\
- \\
0.9\end{array}$ & $\begin{array}{c}\mathbf{4 8 . 4} \\
\text { traces } \\
- \\
- \\
- \\
- \\
1.9 \\
4.8 \\
2.0 \\
4.4 \\
5.6 \\
4.1 \\
9.6 \\
12.0 \\
-\end{array}$ \\
\hline $\begin{array}{l}\text { Others } \\
\text { 2(3H)-Furanone, dihydro-4-hydroxy } \\
\text { Aniline, N-methyl } \\
\text { Formamide, N-methyl-N-phenyl } \\
\text { Dibenzofurane }\end{array}$ & $\begin{array}{c}\mathbf{1 . 4} \\
- \\
0.9 \\
\text { traces } \\
0.5\end{array}$ & $\begin{array}{l}\text { traces } \\
\text { traces } \\
\quad- \\
- \\
-\end{array}$ \\
\hline
\end{tabular}

* The total ion currents generated depend on the characteristics of the compound and are not a true quantitation.

trace $<0.1 \%$. 


\section{Volatiles}

The volatile compounds were obtained by distillation-extraction of the total lipophylic extract, analyzed by GC/MS, and 34 compounds were identified. The results are summarized in Table II.

The composition of the volatiles was very complex, analogously to the other investigated marine invertebrates. Contrary to the sterols, whose composition was similar in both investigated tunicates, the composition of the volatiles in the investigated tunicates appeared to be entirely different.

Among the identified volatiles the most interesting ones appear to be the chlorine containing compounds. In Styela sp. we identified two such compounds, belonging to the group of phenols. Pentachlorophenol was found earlier in some Black Sea algae (Kamenarska et al., unpubl. results). In Phallusia sp. there were no such phenols, but we identified a group of chlorinated hydrocarbons. Hexachloroethane, the main component of the volatiles, belongs to this group. Earlier similar compounds with 3-4 chlorine atoms have been identified in the Black Sea algae Cystoseira barbata (Milkova et al., 1997) and in some Gorgonians (Frette, unpubl. results). Such compounds are known to possess antibacterial and fungicidal properties and may be considered to have defensive functions in the organisms. The biological halogenation by algal haloperoxidases is considered to lead to the emission of volatile halogenated compounds. These are recognized as substrates that destroy the ozone layer. It has also been demonstrated that they are involved in the defense mechanism (allelopathy) of the algae (Takashi et al., 1999) Such compounds can be biosynthesized in algae and transferred to the invertebrates through the diet. Probably, because of their defensive functions, they accumulate in the tunicates.

Other potentially defensive compounds were 2-methoxyphenol in Phallusia sp. and benzoic acid in Styela sp. Acids, aldehydes, ketones and diethyl sulfone were found only in Styela sp. Some of these compounds, especially aldehydes, might possess some attractant-type activity.

Another significant difference between the investigated tunicates was the concentrations of the hydrocarbons. In Phallusia sp. their composition was very simple and the concentrations were low. There was a similarity to the volatiles of Botryllus schlosseri, which belongs to the same family (Ascidiidae). However, in Styela sp. the concentrations of the hydrocarbons were significantly higher. Part of them were n-alkanes and those with odd number of carbon atoms prevailed, as expected. Anthracene, one olefinic and several cyclic hydrocarbons were also identified in this tunicate.

\section{Lipids}

The methyl esters of the fatty acids are summarized in Table III. The two species strongly differ in the TAG/PL ratio, gravimetrically determined. In Styela sp. TAG were $98.5 \%$ of the total lipid mixture and PL were only $1.5 \%$. However, in Phallusia sp. phospholipid concentration was four times higher than that of triacylglycerols. This difference can be used for chemotaxonomic studies.

The fatty acid composition was typical for higher plants and invertebrates. The main fatty acids were palmitic acid and oleic acid, while the concentration of polyunsaturated fatty acids (PUFA) typical for marine organisms was relatively low.

It appears that the fatty acid composition of TAG and PL shows some differences, mainly in

Table III. Fatty acid composition of Styela sp. and Phallusia sp (\% of total fatty acids).

\begin{tabular}{|c|c|c|c|c|}
\hline \multirow[b]{2}{*}{ Fatty acid ${ }^{\mathrm{a}}$} & \multicolumn{2}{|c|}{ Styela sp. } & \multicolumn{2}{|c|}{ Phallusia sp. } \\
\hline & TAG $(\%)^{\mathrm{b}}$ & PL $(\%)^{b}$ & TAG (\%) & PL (\%) \\
\hline 14:0 & 4.7 & 1.8 & 9.3 & 3.8 \\
\hline $14: 1$ & - & 1.9 & - & - \\
\hline $15: 0$ & 0.9 & 0.7 & - & - \\
\hline $16: 0$ & 25.4 & 22.4 & 29.1 & 18.4 \\
\hline $16: 1 *$ & 5.7 & 3.3 & 8.1 & 2.6 \\
\hline $16: 3$ & 1.0 & 1.1 & - & - \\
\hline $16: 4$ & 1.0 & 1.3 & - & - \\
\hline $17: 0$ & 3.5 & 8.6 & - & - \\
\hline 18:0 & 8.3 & 9.7 & 11.0 & 16.1 \\
\hline $18: 1 *$ & 18.4 & 11.8 & 18.3 & 33.3 \\
\hline $18: 2 *$ & 8.2 & 4.8 & 2.5 & 4.3 \\
\hline $18: 3$ & 2.8 & 2.6 & - & 1.5 \\
\hline $18: 4$ & 3.6 & 3.0 & 0.8 & 0.6 \\
\hline $20: 1$ & 1.4 & 1.4 & 5.5 & - \\
\hline $20: 4 / n-6 /$ & 3.7 & 5.7 & 2.0 & - \\
\hline $20: 4 / n-3 /$ & 0.5 & 1.2 & - & - \\
\hline $20: 5 / n-3 /$ & 10.7 & 10.3 & 1.8 & 10.4 \\
\hline $22: 1$ & 0.5 & 0.5 & 7.1 & 6.5 \\
\hline $22: 5 / n-3 /$ & - & 1.2 & 4.4 & 2.44 \\
\hline $22: 6 / n-3 /$ & - & 7.0 & - & - \\
\hline
\end{tabular}

a Values obtained from three parallel measurements.

b TAG means triacylglycerols, PL means phospholipids. * More than one isomer. 
Phallusia sp. In this animal TAG contained more $\mathrm{C}_{16}$ and less $\mathrm{C}_{18}$ acids than in the phospholipids from the same invertebrate. In Styela sp. the polyunsaturated fatty acids 22:5 and 22:6 were concentrated entirely in the phospholipids.

The fatty acid composition of both invertebrates showed significant differences. Phallusia sp., contrary to Styela sp., did not contain any 16:3, 16:4 and 17:0 acids and in addition the concentration of arachidonic acid appeared unusually low for a marine organism. Styela sp. was characterized by the presence of $22: 6$ acid and by a higher concentration of a 20:5 acid in the triacylglycerols.

Akihisa T., Tamura T., Matsumoto T., Kokke W., Ghosh P. and Thakur S. (1990), (22Z,24S)-stigmasta-5,22,25trien-3-ol and other novel sterols from Clerodendrum scandens. First report on the isolation of cis- $\Delta^{22}$-unsaturated sterols from a higher plant. J. Chem. Soc. Perkin Trans I, 2213-2218.

Ballantine J., Lavis A. and Roberts J. (1977), Marine sterols. XV Sterols from some oceanic holothurians. J. Exp. Mar. Biol. Ecol. 30, 29-35.

Christie W. (1973), Lipid Analysis, Pergamon Press, Oxford, pp.38-39.

Dembitsky V. (1979), Plasmalogens in phospholipids of marine invertebrates. Biol. Morya 5, 86-90 (Russ).

Dembitsky V., Shkrob I. and Dor I. (1999), Separation and identification of hydrocarbons and other volatile compounds from cultured blue-green alga Nostoc sp. by gas chromatography-mass spectrometry using serially coupled capillary columns with consecutive nonpolar and semipolar stationary phases. J Chromatogr. A682, 221-229.

De Rosa S., Milone A., Popov S. and Andreev S. (1999), Sterol composition of the Black Sea hydrozoan Obelia longissima (Pallas 1766). Comp. Biochem. Physiol. 123B, 229-233.

Elenkov I., Ivanova A., Stefanov K., Seizova K. and Popov S. (1993), A quantitative determination of lipid classes in higher plants and algae by a gas-chromatographic procedure. Bulgarian Chem. Commun. 26, 98-103.

Elyakov G. B. and Stonik B.(1988), Sterols from marine invertebrates. In: Steroids from Marine Organisms (Kamernitskii A. B., ed.). Moscow, Nauka, pp. 123 125 (Russ).

Faulkner D. (1995), Marine natural products. J. Nat. Prod. Reports 12, 256-258.

Goad L. (1978), The Sterols of Marine Invertebrates: Composition, Biosynthesis, and Metabolites. In: Marine Natural Products, Chemical and Biological Perspectives Vol. 2 (Scheuer P. J., ed.). New York, Academic Press, pp. 75-172.

Guyot M. and Durgeat M. (1981), Occurrence of 9(11)unsaturated sterol peroxides in Tunicates. Tetrahedron Lett. 22, 1391-1392.

Guyot M. and Davoust D. (1982), Hydroperoxy-24-vinyl-24-cholesterol, nouvel hydroperoxyde natural

\section{Acknowledgement}

The authors are grateful to Bulgarian National Council for Scientific Research (project X-710) and the Scientific and Technical Research Council of Turkey (TÜBİTAK) (project SBAG 1818) for the partial financial support of this work. Very special thanks are due to Dr. Rosano Moreira da Rocha (Univ. Federal do Parana/Brasil) for identification of the tunicates. Also thanks to Dr. Chris M. Ireland (University of Utah/USA) for helping about identification. Special thanks are expressed to pharmacist M. Alptekin Arat (Hacettepe University/Turkey) and biol. Murat Bilecenoğlu (Ege University/Turkey) for collecting the specimens.

isole de deux tuniciers: Phallusia mamillata et Ciona intestinalis. Tetrahedron Lett. 23, 1905-1906

Hendriks H., Geerts J. and Malingre Th. (1981), The occurrence of valeranone and crypto-fauronol in the essential oil of Valeriana officinalis L. s.1. collected in the northern part of The Netherlands, Pharm. Weekblad, Sci. Edition. 116, 1316-1320.

Kostetsky E., Naumenko N. and Gerasimienko N (1983), Phospholipid composition of tunicates. Biol Morya 2, 51-56 (Russ).

Kostetsky E. and Naumenko N. (1984), Comparative study on fatty acid composition of phospholipids in marine invertebrates. Khim. Prir. Soed. 24-29 (Russ).

Milkova T., Talev G., Christov R., Dimitrova-Konaklieva S. and Popov S. (1997), Sterols and volatiles in Cystoseira barbata and Cystoseira crinita from the Black Sea. Phytochemistry 45, 93-95.

Popov S., Marekov N., Konaklieva M., Milkova T., Stoilov I., Demirev P., Mollova N., Andreev S. and Dimitrova S. (1988), Sterols from some Black Sea algae and invertebrates. Inform. Bull. Inst. Okeanology Acad. Sci. USSR 30, 28-34 (Russ).

Schmitz F. J. (1977), Uncommon marine sterols. In: Marine Natural Products, Chemical and Biological Perspectives, Vol. 1 (Scheuer P. J., ed.). New York, Academic Press, pp. 241-297.

Slantchev K., Popov S. and Andreev St. (2000), Sterol composition of Tunicates. Bulg. Chem. Ind. 71, 31-35.

Slantchev K., Stefanov K., Seizova K., Popov S. and Andreev S. (2000a), Chemical composition of the lipophylic extract from the tunicate Botryllus schlosseri. Z. Naturforsch. 55c, 794-798.

Takashi O., Satoru N., YoshinoriT., Minoru S. and Yoshikazu I. (1999), Occurrence of bromoperoxidase in the marine green macro-alga, Ulvella lens, and emission of volatile brominated methane by the enzyme. Phytochemistry 52, 1211-1215.

Volkman J. K., Rijpstra W., de Leeuw J., Mansour M., Jacson A. and Blackburn S. (1999), Sterols of four dinoflagellates from the genus Prorocentrum. Phytochemistry $\mathbf{5 2}, 659-668$.

Zollo F., Finamore E., Gargiulo D. Ricco R. and Minale L. (1986), Marine sterols. Coprostanols and $4 \alpha$-methyl sterols from Mediterranean tunicates. Comp. Biochem. Physiol. 85B, 559-560. 